\title{
Empirical Verification of Swanson's Caring Processes Found in Nursing Actions: Systematic Review
}

\author{
Mary Kalfoss*, Jenny Owe \\ Diakonova University College, Oslo, Norway \\ Email: "Mary.Kalfoss@diakonova.no,Jenny.Owe@diakonova.no
}

Received 7 October 2015; accepted 8 November 2015; published 11 November 2015

Copyright (C) 2015 by authors and Scientific Research Publishing Inc.

This work is licensed under the Creative Commons Attribution International License (CC BY). http://creativecommons.org/licenses/by/4.0/

\section{(c) (i) Open Access}

\begin{abstract}
Caring has long been recognized as central to nursing and is increasingly posited as a core concept although developing a theoretical description of caring which is adequate in the $21^{\text {st. }}$ century continues to be a difficult task for nursing scholars. Consequently, verifying existing theoretical structures of caring remains an ongoing challenge. The aim of this article is to provide empirical verification of the caring processes of "knowing," "being with," "doing for," "enabling" and "maintaining belief" from Swanson's Middle Range Caring Theory based on the categorization of nursing actions from a systematic literature review on care. Methods: A systematic literature review was conducted in the fields of nursing sciences, medicine and psychology. Purposeful sampling was carried out covering a period from 2003-2013. The final sample included 25 articles. Results: Major themes of nursing actions included "knowing" which consisted of centering, nurturing, informed understanding, assessment skills, communication and respect for individual differences. "Being with" was characterized by intimate relationship, connecting, presencing, emotional adaptability awareness of self/other and decentering. "Doing for" included competence, knowledge, professional/technical skills, helping actions, anticipatory, multidisciplinary and preserving dignity. "Enabling" was characterized by self care, commitment, complexity of care, appropriate communication, information/education, sharing power, enabling choice and ongoing validation. Finally, "maintaining belief" was characterized by spiritual being, humanistic view, harmonious balance, hope, love, and compassion, meaning, and religious and spiritual orientation. Conclusion: Empirical verification was shown for the caring processes described in Swanson's Caring Theory grounded in concrete nursing actions.
\end{abstract}

\section{Keywords}

Caring Processes, Empirical Indicators, Nursing Actions, Semantics,

Corresponding author. 


\section{Swanson's Middle Range Caring Theory}

\section{Introduction}

As evidenced by our history, practice and scholarship, caring has long been recognized as central to nursing and is increasingly posited as one of the core concepts of an evolved nursing science [1]-[4]. However, developing a theoretical description of caring that is adequate in the $21^{\text {st }}$ century continues to be a difficult task for scholars in nursing and health science professions. Presently, there exist many theoretical critiques surrounding the concept of caring in nursing science. At one end of the spectrum, some of these critiques are centered on "reducing a complex, subjective intersubjective relational, often private human phenomenon to a level of objectivity that exhausts, trivializes and delutes its authenticity and deeper meaning” as stated by Watson ([4], p. 3). At the other end of the spectrum, Lee and colleagues assert that nursing research in caring must "move forward to examine the frequency of caring behaviors performed by nurses in patient care, clinical conditions that affect the delivery of caring, and effects of caring on practice and health outcomes” ([5], p. 8).

Indeed, in his seminal work, Kuhn [6] declares that theory, be it explicit or implicit, plays a key role in understanding any behavior, and underlines that there is nothing as useful as a good theory. Consequently, verifying exiting theoretical structures of caring has been described as an ongoing challenge in the discipline of nursing although attempts to verify the theoretical structure of caring have been described as rare. Moreover, Cossette and colleagues succinctly declare that it is time for theorists, educators and clinicians to group around the middle age theory that can be tested in empirical research [7]. The aim of this article is to provide empirical verification of the caring processes "being with,” doing for, "enabling,” and "maintaining belief” from Swanson’s Middle Range Caring Theory grounded in concrete nursing actions from a systematic literature review.

\section{Description of Swanson's Caring Processes}

Swanson published her middle range theory of caring in 1991 and 1993. Her theory of caring was empirically developed from three phenomenological studies in separate perinatal contexts [8]-[10]. On the basis of these studies, she formed a definition of caring which she expressed as "caring is a nurturing way of relating to a valued other toward whom one feels a personal sense of commitment and responsibility [3] [11] [12]. Swanson’s middle range theory of caring includes five caring processes. Knowing is characterized as striving to understand an event as it has meaning in the life of the other where the care provider works to avoid priori assumptions about the meaning of an event. The carer instead, centers on the one cared for and conducts a thorough, ongoing cue-seeking assessment of the experience of the one cared for. Integral to knowing is the carer's philosophy of personhood and the willingness to recognize the other as a significant being. When knowing occurs, the selves of both provider and recipient are engaged ([3], p. 215-216). Being with is portrayed as being emotionally present to the other. It invites "being there" conveying ongoing availability and sharing feelings whether joyful or painful. The presence and sharing are responsibly monitored so that the one caring does not ultimately burden the one being cared for. Being with, goes a small step beyond knowing. It is more than understanding another's plight, it is becoming emotionally open to the other's reality, where the others experience matters to the one caring ([3], p. 216). Doing for entails doing for the other what she or he would do for the self if it were possible. Care that is doing is comforting, protective of the other's needs, performed competently and skillfully and grounded in preserving the dignity of the other ([3], p. 216-217). Enabling is facilitating the other person's passage through life transitions and/or unfamiliar events. The purpose is to facilitate the other's capacity to grow and actualize oneself, heal and/or practice self care. It involves focusing on the event, informing, explaining, supporting allowing and validating feelings, generating alternatives, thinking things through and giving feedback ([3], p. 217). Maintaining Belief is sustaining faith in the other's capacity to get through an event or transition and face the future with meaning. It involves holding the other in esteem and believing in them. The one caring maintains a hope-filled (as opposed to a hope-less) attitude. In maintaining belief the carer belief seeks to assist the other in attaining, maintaining, and regaining meaning from their experiences ([3], p. 217-218). 


\section{Materials and Methodology}

\subsection{Sample and Procedure}

A systematic literature search was conducted in the fields of nursing sciences, medicine and psychology. Purposeful sampling was carried out covering a period from 2003-2013. The data bases Cinahl, Medline, Embase, and PsycInfo were used with the assistance of a librarian who developed search strategies adapted to each database. The term care was searched in combination with following key words: Care AND Concept Analysis AND limitations which included timeline, Review OR Systematic Review OR Metasynthesis OR Meta-analysis OR Narrative review. The search resulted in 414 citations. The title and abstract of all 414 citations were printed and two reviewers (MK and JO) independently reviewed each title and abstract for eligibility. During this process, 219 citations were excluded due to the titles not being relevant, were in duplicate form, and/or written in a language which was not English. The 123 citations which were found relevant were retrieved for detailed evaluation. The titles and/or abstracts of these 123 articles were read again by the two reviewers independently. Inclusions criteria included having either the word care/caring in the title or in the abstract, were written in English, and were a form of concept analysis, a systematic review, meta analysis or metasynthesis. Duplicate citations were again excluded. This process resulted in 35 articles which were fully retrieved. After detailed reading, a further 6 articles were deleted as they did not discuss care or caring per se, did not apply an explicit method of concept analysis or the findings did not reflect the perspectives of staff, care recipients, or family members. Upon the second reading of the 29 articles, a further 4 were excluded because they did not discuss care or caring per se or explain their literature review methodology. All decisions to exclude articles were based on consensus between the reviewers. The final sample included 25 articles. No further references were attempted located by hand searching, manual scanning lists of relevant articles or gray literature (see Figure 1).

\subsection{Data Analysis}

During data collection and analysis, each article was read attentively to identify the general idea of the work and the meaning of the caring concept as described by the authors. The analysis was carried out according to the thematic analysis procedure as described by Miles and Huberman [13]. A mixed classification grid which included attributes, antecedents, nursing actions and outcomes were developed. The data categorized under the category nursing actions is the focus of this paper. First, the data findings were loosely categorized at broad, topical levels according to Swanson's caring processes. Then clusters of phenomenon were categorized using a constant comparative method. For each of the categories, data was read thoroughly and assigned descriptive words. An attempt was made to preserve the rich details of the findings as descriptions at the cluster levels. The second author (JO) read through the classification schemes, raised questions and suggested alterations. Both authors discussed the classification of findings until agreement was reached. A log book allowed the authors to trace more easily the various steps followed during these processes, thereby supporting the reliability of the study. Team work during data collection and analysis allowed to take into account the subjectivity of the researchers, thus improving the credibility of the study [14].

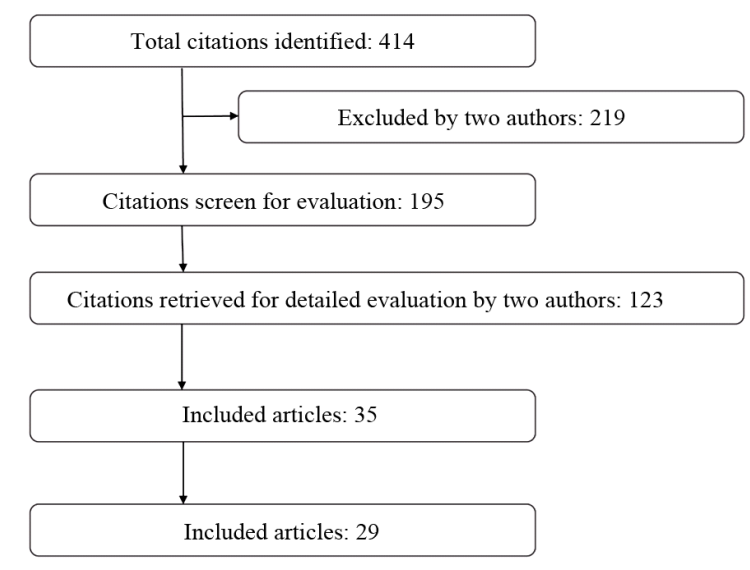

Figure 1. Literature identification process. 


\section{Results}

\subsection{Knowing and Empirical Indicators}

Knowing focuses on centering on the other which includes having a humanistic view of the person [15]-[18]. It also seeks to gain insight to and understanding of another's situation with a process of interpretation, sensitivity, inference, empathy, intuition, intellectual cognition and imagination [19]. Other characteristics include actively attempting to understand and identify the other's meanings, cognitive appraisals, concerns and interpretations of their situation and their perception of their relationships with the caregiver [20]-[22]. The literature also described being physically and mindfully present [20], displaying attentiveness, engagement, and being deeply involved and going beyond routine [20] [22] [23].

Knowing also emphasizes a nurturing way of relating to a valued other [1] [15] [22] where key factors include treating patients as unique persons [16] [24] with an attitude of respect [1] [20] [22] [25] [26] and being non-judgmental [20] and respectful of the other's wishes [17].

Knowing includes an informed understanding of the other. Main characteristics embody having detailed knowledge of the other's experience and needs [15] [27], using experience-based information [19] with good knowledge of clinical practice and well developed assessment skills [20] [27] [28] in data gathering, clinical reporting and documentation [19] and excellent verbal and non-verbal communication [15] [18]-[21] [25] [27] with emphasis on open dialogue.

Integral to knowing is the necessity of conducting a comprehensive individual assessment which is holistic. The health professional assesses existing physical psycho spiritual [20] and existential needs [24] with consideration of patients perceptions, beliefs, values and wishes [16] [17] [23] and appreciation of family traditions [29]. Knowing is considered context specific and entails an ongoing and crisis orientated assessment [20] which is culturally sensitive with acceptance for variability [18] [20] The process of knowing includes showing respect for individual differences by assessing demographic data, age, gender, marital status, education, social influences from cultural backgrounds, health care experiences, length of stay, environmental resources such as payment expectations, government and other agencies [22].

\subsection{Being With and Empirical Indicators}

The process of being with includes an intimate caregiving relationship characterized by expert nursing practice, interpersonal sensitivity and intimate relationships [20]. Interpersonal sensitivity is regarded as intuitive, empathetic insight into another's suffering and an imaginative process where caregivers symbolically and metaphorically place themselves into a patient's shoes to gain a multidimensional understanding of a patient's thoughts and feelings [23]. Being with also consists of being creative and daring and being firm and doing things that the patient does not like [20].

Being with is based on connecting, bonding and attachment [16]. Some literature describes intimate relationship as the perpetual existence of a bond and covenant which embodies caring benevolence [29]. Other characteristics of being with include mutual trust [30] availability [20] reciprocal linking [19] [20] [29] and constancy, endurance and adaptability within a stable relationship [20] [29]. Other key factors in being with are being protective [15] and displaying cautiousness in avoiding harm and danger [15] [20]. In being emotionally present, the health professional is emotionally open to the other's feelings and attempts to calms fears [20] [22] is comfortable in sharing thoughts and feelings, also with family [20]. However, the health professional can experience strong emotional feelings such as joy, highly cherishing and love [15] as well as anger, weariness, and irritation [20]. Conversely, hurried and mechanical caring [20] versus caring with a warm, reassuring manner and complete engagement [23] can be considered an anti thesis to being emotionally present.

Being with also includes authentic presencing [24] with key aspects including showing interest, concern and engagement [1] [23], being compassionate and empathetic [16] [19] [22], sympathetic [19] [23] honest and sincere [15] and sensitive [18]. Authentic presencing is also described as a way of being [15].

Being with also embraces emotional adaptability. Key factors include becoming deeply involved without becoming overly emotional, destructive, controlling and self centered [20]. Other defining qualities include expressing surface and deep emotions during encounters either in deep acts or surface acts. Emotional adaptability consists of awareness of self and other where the professionals use themselves therapeutically [23]. One can protect oneself in a positive manner, have spiritual/philosophical beliefs, can manage personal vulnerability and 
have the ability to tolerate uncertainty [1]. Emotional adaptability is also reflected in the nurses' consciousness and work persona and includes work experience [19]. Awareness of the impact of personal qualities such as age, nurses past and impact of social norms and societal culture on self [16] [19] [30] is also reflective of emotional adaptability. Being with is also characterized by decentering which include characteristics such as the ability to maintain a degree of objectivity in therapeutic relationships where one attempts to understand and put aside or inhibit own impulses making a conscious effort to differentiate one's view from the view of another [19]. It also takes into consideration one's attitudes towards the other and positioning within relationships [19] [31].

Conversely, emotional adaptability can be threatened by emotional demand, interaction frequency, and work complexity which can result in high stress experiences [19]. Reduced emotional adaptability can also contribute to depersonalization, reduced output and endurance, diminished performance, loss of empathy, poor judgment and compassion fatigue [32]. Health professionals experiencing emotional demand, use emotional labor strategies such as standing back, hardening, professional face, going with the flow, negotiation and accommodation, and containing and avoidance of too much liking or disliking [23] (see Figure 2).

\subsection{Doing for and Empirical Indicators}

Doing for is also multifactorial with a focus on professional competence [15] [20] [30]. Characteristics of professional competence include education and training [25] clinical knowledge [15] [22] professional and personal qualities and ongoing adjustment [15] [16] [30] learning [15] collective skills [19] skill mix [16] and self confidence [15] [20] [30]. Indicators of professional competency include detecting, preventing, listening, anticipating, educating, advocating, monitoring and practicing surveillance which can produce both positive and negative outcomes [15]. Providing reassurance, support, comfort, acceptance, legitimacy, confidence, promoting healing, reducing injury and suffering and providing for physical and emotional needs are also characteristics of professional competency [23].

Professional competence also includes adequate knowledge in providing care [15] [25] and involves professional attitude, professional presentation and caring capacities [22]. Providing care is task or procedure planned, occurs in and is influenced by context, is directed by process, skilled, safe, experiential, coordinated, individualizes, collaborates and is evidence based [15]. Competence is also shown in the development and execution of expert therapeutic physical psycho spiritual nursing interventions [28] and providing individualized, holistic care

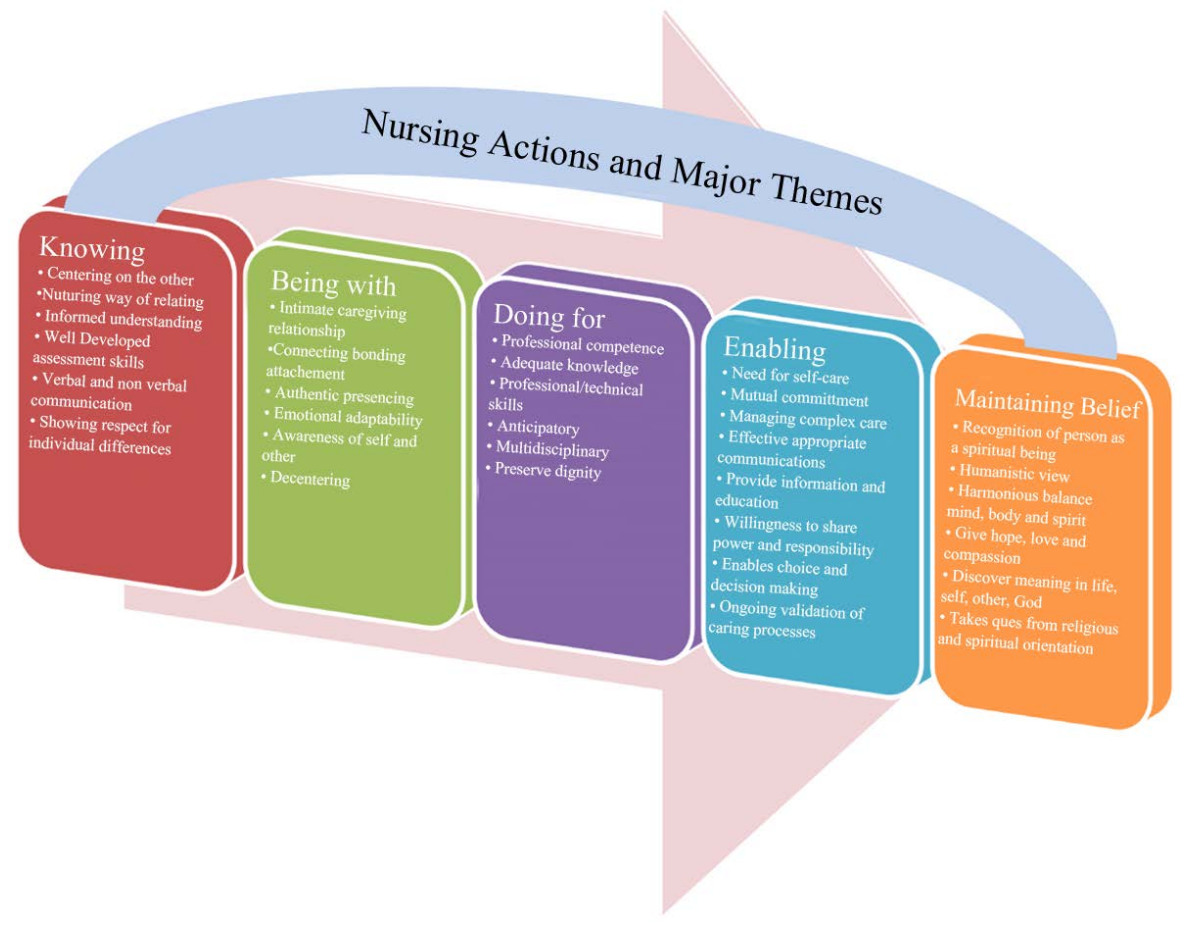

Figure 2. Major themes and sub-themes found in nursing actions. 
that maximizes growth and development [17] [24] [30]. Professional competence also includes professional/technical skills [15], regarding procedures, tests and administering medications [22], demonstrating thorough effective management of all symptoms assessed [17], minimizing toxicity [24] and in the provision and/or management of pain relief [22]. Conversely, lack of clinical experience, education, patient assessment skills and educational training contribute to professional incompetence [28].

Comforting helping actions are also a corner stone of professional competency [15] which include concern for patient's privacy, prompt in response, listening and giving time to speak [22] using touch [18] [20], imagery and prayer [18] with eye contact and verbal reassurance [20].

Doing for is also anticipatory in that the professional initiates care early with interdisciplinary team work [24]. It also consists of advance planning with discussion on preferred place of death and includes extended family, with community and pastoral support [18]. It also has a multidisciplinary approach, educates and trains team members on effective communication techniques, clarifies roles and responsibilities, refers patients, mobilizes instrumental tangibles and emotional support from family, peers, community members and the health care team [17] [25] [31] and encourages colleagues to express their concerns [20].

Doing for is grounded in preserving the dignity of the other. Conversely, patients lose their value and dignity as human beings due to nursing abuse. Patients can suffer from uncaring encounters described as unintentional events, also including intentional harm. Cultural and structural elements in the encounter can also be uncaring resulting in carelessness with delays in treatment and inappropriate management of acutely well patients [28] [33], leading to enmeshment and exploitation [1].

\subsection{Enabling and Empirical Indicators}

In enabling, there exists a need for self-care [25], which is impacted by the patient's intrinsic motivation, competence and self determination [22]. It focuses on regarding patients as partners, in a collaborative symmetrical relationship with interactive assessment of patient's knowledge and self management skills [25]. It also involves mutual commitment of both professional and other to engage in the healing process and the sharing of common goals [29].

Enabling also consists of how professionals manage complex care which requires ongoing personal adjustments, navigating a plan of care, concurrently managing interactions within the health system, providing education and supportive interventions with the purpose of increasing patient's skills and confidence in managing health problems [25]. Conversely, lack of recognition of patient deterioration, failure to appreciate clinical urgency, incomplete and missing patient documentation and/or difficult documentation which are difficult to read can decrease quality care [28].

A cornerstone of enablement is providing effective/developmentally appropriate communication with patients and family. This involves providing communication regularly, clearly, accurately, honestly and empathetically in regards to family dynamics, cultural and religious beliefs and previous experience with loss, also considering the nature of the illness [26]. Communication also embodies providing information and educating [20], such as explanation about the other's care, medications, tests, and overall condition [22], providing written materials, phone calls, emails, internet use, independent learning with software and telehealth systems monitoring, coaching and counseling [25] as well as providing information which isn't welcome [20].

Willingness to share power and responsibility is also a characteristic of enabling [20] [26] [34]. Both parties must be able to accept the power relation and recognize each others' expertise, with acceptance of mutual dependency [26]. Enabling also consists of empowerment partnership and mutuality with family. Mutuality is care which is open and characterized by wanting to be of help and accepting help from each other with dignity [26]. Partnership between patients/professionals emphasizes shared responsibility, information, care taking, having access to information about the family and recognizes the family member as an important source of information. It incorporates defining role and responsibilities in collaboration, allowing family members to choose their degree of involvement, and support of family emotions with sensitivity to individualized needs. Partnerships also concentrate on family strengths with accepting individuality and diversity and enables choice and decision making. It includes respectful coalition between health care team, patient and family [16] [22] [24] [25] honoring family choices [21] and uses patient's wishes to guide activity [16].

Enabling emphasizes ongoing validation of caring processes which are evidenced based [20]. Ongoing validation requires that caring outcomes should be measured and defined [15] although the literature underlines the 
need for the development and testing of quality of life instruments in order to establish appropriate outcomes measures [17] and questionnaires assessing patient suffering [33]. Barriers to enabling include lack of clear description of measureable behaviors and patient outcomes [15] [16] [23] and the need to evaluate existing instruments to verify accurately whether they reflect caring attributes [25].

\subsection{Maintaining Belief and Empirical Indictors}

Maintaining belief is grounded in recognition of a person as a spiritual being with a belief in God, a supernatural being, a life force, with a dynamic quest for a transcendent relationship [18]. Maintaining belief is based on a humanistic view of the person [18], respects individual differences and treats patients as a unique person [16] [22] and considers the whole patient [15]-[18] [24]. Maintaining belief also accepts other people as they are [15] and understands the need for the maintenance of a harmonious balance between body —mind-spirit [29]. Maintaining belief is grounded in giving hope, love, and compassion and it helps with the quest to discover meaning in life, with self, other-God, with regard to issues of suffering [15] [18] and taking cues from the person's religious and spiritual orientation [18] (see Figure 2).

\section{Discussion}

Defining caring and its empirical indicators is an ongoing challenge in the discipline of nursing. Fawcett [35] underlines the importance and need for a distinctive nursing language which she states is mandatory if nursing is to advance as a discipline. The findings of this study showed that the descriptions of Swanson's caring processes had semantic relevance and clarity as a conceptual framework for the categorization of nursing actions from a systematic literature review. The semantic clarity of Swanson's concepts has also been supported by others [36] [37]. The empirical findings also contribute to the construct validity of Swanson's caring processes.

Findings also lend empirical support to Swanson's definition of nursing as a "nurturing way of relating to a valued other toward whom one feels a personal sense of commitment and responsibility" [11]. The findings also give external validity to the key words in her definition described as nurturing (growth and health producing), a way of relating (occurs in relationships), to a valued other (the one cared for matters); toward whom one feels a personal (individualized and intimate), sense of commitment (bond, pledge, or passion) and responsibility (accountability and duty). Whereas, this definition applies to all caring relationships, relationships of central concern for nursing include nurse to client, nurse to nurse and nurse to self [12]. Further, the empirical indicators from this study are based on findings from a vast array of samples. Results, therefore, also provide empirical evidence for past claims that her theory demonstrates its ability to be "broadly generalizeable across different populations" and meets the middle-range standard for having a "high explanatory value" in understanding of different phenomena ([36], p. 598).

Certain scholars have stated another major challenge to nursing professionals is the measuring of caring that occurs within the complex and evolving environment of health care. The ability to transform theory into practice through research is a critical bridge to measuring quality nursing care. Thoughtful investigation of the empirical indicators of caring in this study is an example of this transformation [2]. Indeed, Swanson ([3], p. 63) recently underlined that further investigations are needed to develop research measures with which to quantify caring capacity, explore the origins of caring capacity, examine the effects of nurturing and experience on caring capacity and examine relationships between the capacity for caring and the actual occurrence of caring practice. It is hoped that the empirical indicators uncovered in this study could be used to contribute to the development and validation of new and existing instruments for measuring caring indicators as related to Swanson's middle range theory and others.

On the other hand, the structure of caring as proposed by Swanson is described as 5 interrelated caring processes in that categories are not mutually exclusive. In trying to classify the findings under the separate processes, problems were encountered by the authors in that certain empirical indicators could be categorized under more than one process. For example, aspects of professional knowledge and skills could be regarded an empirical indicator in both Knowing and Doing For. Some of the subcategories in Knowing could also apply for all the other caring processes, just as the subcategories found in Being With could also be descriptive of other caring processes as well. Furthermore, the process Being With was found to be much more comprehensive than just becoming emotionally open to the others' experience as described by Swanson. This finding has been confirmed by others [36]. Admittedly, also some of the sub-dimensions describing Enabling and Maintaining Belief 
could also be integral to other caring processes. Consequently, the separation of the caring indicators into five different processes may represent an artificial and reductionalistic way of separating caring, knowing, being and doing within nursing responses to the human experience of health. Indeed, one may question if caring is central to nursing, can knowing be separated from doing within the nurse-patient relationship? Interestingly, Watson [4] describes caring as a way of being which involves being, knowing and doing all at once. Our difficulties in the separation of overlapping caring processes could support the conception of caring as a way of being which includes the other caring processes. Also, in an earlier study which focused on family members' involvement in the care of a dying relative using Swanson's and Watson's caring theories with a focus on three main categories to know, to be and to do, the author's found that the categories did not have distinct boundaries but instead partially overlapped one another ([36], p. 46).

Nevertheless, Swanson's theory has developed over the years to further enhance individual descriptive components of each process and the main five concepts have remained static. An example of this maturation process is the addition of helping to find meaning in the "Maintaining Belief" process, which includes affirming the clients experience and meaning they derive from it, as well as being cognizant of an individual's spiritual and religious needs. Swanson's theoretical constructs (caring processes) reflect and remain consistent with Jean Watson's Theory of Transpersonal Caring, and these two are often cited together [38] contributing her theory with a higher level of credibility.

Meriting comment is the fact that very few findings were found which were related to the moral dimension of nursing practice. The authors found this surprising as nurses are constantly experiencing new ethical issues as a result of global developments and changes in health care. One nursing scholar has explicitly stated that there exists a scarcity of ethical features in nursing theories generally and criteria for evaluating theories' ethical dimension [39]. From a philosophical perspective, ethical knowledge can be construed in terms of its ontological and epistemological dimensions [40]. Our findings also found a paucity of information regarding the ontological and epistemological grounding in the studies reviewed. Consequently, the ethical components pertinent to Swanson's theory need to be made explicit if her theory is to guide practice. For example, it would be helpful in the future if more elaboration of the ethical principles relevant to the theory could be made more explicit. Further, the propositions of Swanson's theory do not offer clear guidance for ethical decision making. Swanson neither addresses the ethical dilemmas that might ensue when the nurses' values conflict with client choices. Such information could add to the clarity to the caring processes.

\subsection{Relevance to Praxis}

It has been stated that the goal of nursing theory is to contribute to the wealth and knowledge required for clinical practice in a variety of settings [41]. Recent studies have shown that Swanson's theory can inform practice and lead to near practice approaches as well as investigable factors that influence outcomes that are desired in nursing practice. Numerous hospitals and health care facilities have since adopted Swanson's theory of care as a guide to their own nursing services. Although her theory was originally conceived within a perinatal field, it has been successfully applied across a wide spectrum of nursing care during the past two decades including palliative care, mental disorders, dementia, parental support groups, home care, and critical care among numerous others, demonstrating a parsimonious theory that claims a broad diversity of application within the context of nursing practice.

\subsection{Limitations to the Study}

The biases introduced in this study include the inability to include all of the relevant literature and unpublished material. Certain citations may have been missed during the search stage due to the search words and combinations applied. However, the search strategy adapted for different databases was developed by a librarian. Other terms used with the key words in our search method such a qualitative studies, phenomenology, grounded theory and ethnography could have produced a broader base of relevant literature. Another limitation is that all the articles were written in English, and written by nurses from Western post-industrialized countries and base their findings on the perspective of the nurse. Very few articles were found that were based on the patient perspective which has been supported by others [42]. Further, the searchers' subjectivity remains a bias to thematic analysis although team work decreased this limitation and increased credibility of the work [14]. The identification and naming of codes, themes, sub-themes were discussed by two independent researchers throughout all the phases 
of the analyses. Although language is critically fundamental to the evolution of all disciplines and within any discipline, the selected terminology used in classifying themes and sub themes in this study represents selected terminology denoting specific nursing knowledge. Another bias concerns whether the themes and sub-themes accurately reflect the meanings evident in the data set as a whole. Interpretations of the data may have been enhanced by inviting people with different expertise to discuss the interpretation of the findings. Using Software programs for preparing and instructing the data may have also improved the different categories of description, however, the use of such software packages has also been debated. Finally, our systematic literature review covers the period from 2003-2013. This is a short contemporary view. However, the authors believe that concepts per se are dynamic, impacted by changing sociocultural influences and represent a probable truth at this certain point in time ([43], p. 404).

\section{Conclusion}

Verifying exiting theoretical structures is an ongoing challenge in the discipline of nursing. Results from this study provide empirical validation of Swanson's five caring processes of "knowing”, "being with”, “doing for”, "enabling" and "maintaining belief" in her theory of caring and lend empirical support for her definition of caring. Meleis [44] challenges the perspective that completed theory is the only way to achieve disciplinary status and that outcome is the sole validation of theory. As she pointed out the end product, the process of conceptualizing a phenomenon, the process of understanding a clinical situation and the process of going beyond the data in a research project are the essence of theoretical development. The authors support Meleis's contention. Indeed, Swanson's middle range theory provided a logical structure for the categorization of empirical indicators of caring actions from a systematic literature and contributed to the process of conceptualizing, understanding, and going beyond the empirical data ([5], p. 219).

\section{Acknowledgements}

The authors are grateful to Diakonova University College in Oslo and to the Norwegian Non-Fiction Writers and Translators Organization for financial support of this study. Special appreciation is given to Vidar Brundtland Steder for his help in creating the figure of results. The authors are also appreciative of the work of their anonymous reviewers.

\section{References}

[1] Brilowski, G.A. and Wendler, M.C. (2005) An Evolutionary Concept Analysis of Caring. Journal of Advanced Nursing, 50, 641-650. http://dx.doi.org/10.1111/j.1365-2648.2005.03449.x

[2] DiNapoli, P.P., Nelson, J., Turkel, M. and Watson, J. (2010) Measuring the Caritas Processes: Caring Factor Survey. International Journal for Human Caring, 14, 16-21.

[3] Swanson, K.M. (2013) Empirical Development of a Middle Range Theory of Nursing. In: Smith, M.C., Turkel, M.C., Wolf, Z.R., Eds., Caring in Nursing Classics: An Essential Resource, Springer, New York, 211-221.

[4] Watson, J. (2009) Assessing and Measuring Caring in Nursing and Health Sciences: Jean Watson. Springer Publishing Co., New York.

[5] Lee, M., Larson, P.J. and Holzemer, W.L. (2006) Psychometric Evaluation of the Modified CARE-Q among Chinese Nurses in Taiwan. International Journal for Human Caring, 10, 8-13.

[6] Kuhn, T.S. (1962) The Structure of Scientific Revolutions. University of Chicago Press, Chicago.

[7] Cossette, S., Pepin, J., Cote, J.K. and de Courval, F.P. (2008) The Multidimensionality of Caring: A Confirmatory Factor Analysis of the Caring Nurse-Patient Interaction Short Scale. Journal of Advanced Nursing, 61, 699-710. http://dx.doi.org/10.1111/j.1365-2648.2007.04566.x

[8] Swanson, K.M. (1988) Caring Needs of Women Who Miscarried. In: Leininger, M.M., Ed., Care: Discovery and Uses in Clinical and Community Nursing, Wayne State University Press, Detroit, 55-69.

[9] Swanson, K.M. (1990) Providing Care in the NICU: Sometimes an Act of Love. ANS Advances in Nursing Science, 13, 60-73. http://dx.doi.org/10.1097/00012272-199009000-00008

[10] Swanson-Kauffman, K.M. (1986) Caring in the Instance of Unexpected Early Pregnancy Loss. Topics in Clinical Nursing, 8, 37-46.

[11] Swanson, K.M. (1991) Empirical Development of a Middle Range Theory of Caring. Nursing Research, 40, $161-166$. 
http://dx.doi.org/10.1097/00006199-199105000-00008

[12] Swanson, K.M. (1993) Nursing as Informed Caring for the Well-Being of Others. Image-The Journal of Nursing Scholarship, 25, 352-357. http://dx.doi.org/10.1111/j.1547-5069.1993.tb00271.x

[13] Miles, M.B. and Huberman, A.M. (2002) The Qualitative Researcher’s Companion. Sage, Thousand Oaks.

[14] Creswell, J.W. (2007) Qualitative Inquiry \& Research Design: Choosing among Five Approaches. Sage, Thousand Oaks.

[15] Dalpezzo, N.K. (2009) Nursing Care: A Concept Analysis. Nursing Forum, 44, 256-264. http://dx.doi.org/10.1111/j.1744-6198.2009.00151.x

[16] Pelzang, R. (2010) Time to Learn: Understanding Patient-Centred Care. British Journal of Nursing, 19, 912-917. http://dx.doi.org/10.12968/bjon.2010.19.14.49050

[17] Stayer, D. (2012) Pediatric Palliative Care: A Conceptual Analysis for Pediatric Nursing Practice. Journal of Pediatric Nursing, 27, 350-356. http://dx.doi.org/10.1016/j.pedn.2011.04.031

[18] Tjale, A.A. and Bruce, J. (2007) A Concept Analysis of Holistic Nursing Care in Paediatric Nursing. Curationis, 30, 45-52. http://dx.doi.org/10.4102/curationis.v30i4.1116

[19] Lobchuk, M.M. (2006) Concept Analysis of Perspective-Taking: Meeting Informal Caregiver Needs for Communication Competence and Accurate Perception. Journal of Advanced Nursing, 54, 330-341. http://dx.doi.org/10.1111/j.1365-2648.2006.03815.x

[20] Finfgeld-Connett, D. (2008) Meta-Synthesis of Caring in Nursing. Journal of Clinical Nursing, 17, 196-204.

[21] Malusky, S.K. (2005) A Concept Analysis of Family-Centered Care in the NICU. Neonatal Network, 24, 25-32. http://dx.doi.org/10.1891/0730-0832.24.6.25

[22] Wagner, D. and Bear, M. (2009) Patient Satisfaction with Nursing Care: A Concept Analysis within a Nursing Framework. Journal of Advanced Nursing, 65, 692-701. http://dx.doi.org/10.1111/j.1365-2648.2008.04866.x

[23] Huynh, T., Alderson, M. and Thompson, M. (2008) Emotional Labour Underlying Caring: An Evolutionary Concept Analysis. Journal of Advanced Nursing, 64, 195-208. http://dx.doi.org/10.1111/j.1365-2648.2008.04780.x

[24] Noble, H., Kelly, D., Rawlings-Anderson, K. and Meyer, J. (2007) A Concept Analysis of Renal Supportive Care: The Changing World of Nephrology. Journal of Advanced Nursing, 59, 644-653. http://dx.doi.org/10.1111/j.1365-2648.2007.04383.x

[25] Kawi, J. (2012) Self-Management Support in Chronic Illness Care: A Concept Analysis. Research and Theory for Nursing Practice, 26, 108-125. http://dx.doi.org/10.1891/1541-6577.26.2.108

[26] Mikkelsen, G. and Frederiksen, K. (2011) Family-Centred Care of Children in Hospital—A Concept Analysis. Journal of Advanced Nursing, 67, 1152-1162. http://dx.doi.org/10.1111/j.1365-2648.2010.05574.x

[27] Meghani, S.H. (2004) A Concept Analysis of Palliative Care in the United States. Journal of Advanced Nursing, 46, 152-161. http://dx.doi.org/10.1111/j.1365-2648.2003.02975.x

[28] Quirke, S., Coombs, M. and McEldowney, R. (2011) Suboptimal Care of the Acutely Unwell Ward Patient: A Concept Analysis. Journal of Advanced Nursing, 67, 1834-1845. http://dx.doi.org/10.1111/j.1365-2648.2011.05664.x

[29] Coffey, S. (2006) The Nurse-Patient Relationship in Cancer Care as a Shared Covenant: A Concept Analysis. Advances in Nursing Science, 29, 308-323. http://dx.doi.org/10.1097/00012272-200610000-00005

[30] Hudon, C., St-Cyr Tribble, D., Bravo, G. and Poitras, M.E. (2011) Enablement in Health Care Context: A Concept Analysis. Journal of Evaluation in Clinical Practice, 17, 143-149. http://dx.doi.org/10.1111/j.1365-2753.2010.01413.x

[31] Entwistle, V., Firnigl, D., Ryan, M., Francis, J. and Kinghorn, P. (2012) Which Experiences of Health Care Delivery Matter to Service Users and Why? A Critical Interpretive Synthesis and Conceptual Map. Journal of Health Services Research \& Policy, 17, 70-78. http://dx.doi.org/10.1258/jhsrp.2011.011029

[32] Jenkins, B. and Warren, N.A. (2012) Concept Analysis: Compassion Fatigue and Effects upon Critical Care Nurses. Critical Care Nursing Quarterly, 35, 388-395. http://dx.doi.org/10.1097/CNQ.0b013e318268fe09

[33] Bruggemann, A.J., Wijma, B. and Swahnberg, K. (2012) Abuse in Health Care: A Concept Analysis. Scandinavian Journal of Caring Sciences, 26, 123-132. http://dx.doi.org/10.1097/CNQ.0b013e318268fe09

[34] Wiggins, M.S. (2008) The Partnership Care Delivery Model: An Examination of the Core Concept and the Need for a New Model of Care. Journal of Nursing Management, 16, 629-638. http://dx.doi.org/10.1111/j.1365-2834.2008.00900.x

[35] Fawcett, J. (2005) Contemporary Nursing Knowledge: Analysis and Evaluation of Nursing Models and Theories. F.A. Davis, Philadelphia.

[36] Andershed, B. and Olsson, K. (2009) Review of Research Related to Kristen Swanson’s Middle-Range Theory of Car- 
ing. Scandinavian Journal of Caring Sciences, 23, 598-610. http://dx.doi.org/10.1111/j.1471-6712.2008.00647.x

[37] Wonjnar, D. (2014) Kristin Swanson: Theory of Caring. In: Marriner-Tomey, A. and Alligood, M.R., Eds., Nursing Theorists and Their Work, 8th Edition, Mosby-Elsevier, Maryland Heights, 762-773.

[38] Mason, J. and Wesorick, B. (2011) Successful Transformation of a Nursing Culture. Nurse Leader, 9, 31-36. http://dx.doi.org/10.1016/j.mnl.2011.01.001

[39] Noureddine, S. (2001) Development of the Ethical Dimension in Nursing Theory. International Journal of Nursing Practice, 7, 2-7. http://dx.doi.org/10.1046/j.1440-172x.2001.00253.x

[40] Silva, M.C., Sorrell, J.M. and Sorrell, C.D. (1995) From Carper’s Patterns of Knowing to Ways of Being: An Ontological Philosophical Shift in Nursing. Advances in Nursing Science, 18, 1-13. http://dx.doi.org/10.1097/00012272-199509000-00002

[41] Shaw, M.C. (1993) The Discipline of Nursing: Historical Roots, Current Perspectives, Future Directions. Journal of Advanced Nursing, 18, 1651-1656. http://dx.doi.org/10.1046/j.1365-2648.1993.18101651.x

[42] Sumner, J. (2006) Concept Analysis: The Moral Construct of Caring in Nursing as Communicative Action. International Journal for Human Caring, 10, 8-16.

[43] Penrod, J. and Hupcey, J.E. (2005) Enhancing Methodological Clarity: Principle-Based Concept Analysis. Journal of Advanced Nursing, 50, 403-409. http://dx.doi.org/10.1111/j.1365-2648.2005.03405.x

[44] Meleis, A.I. (1987) Theoretical Nursing: Today’s Challenges, Tomorrow’s Bridges. Nursing Papers, 19, 45-57. 